\title{
Inadvertent placement of pulmonary artery catheter into right carotid artery
}

\author{
Meral Kanbak MD, \\ Turgay Öcal MD
}

Purpose: To report a case of misplacement of a pulmonary artery catheter (PAC) into the carotid artery after open heart surgery.

Clinical features: A 20-mo-old boy underwent open heart surgery (VSD repair ). On the first day postoperatively, he had severe pulmonary hypertension and a PAC was inserted via the left internal jugular approach without complication. Two hours later, chest radiography showed the PAC in the right internal carotid artery which it had reached via the right and left ventricles and aorta. The PAC was withdrawn and a new PAC was inserted and its position was confirmed by chest radiography. Two years later echocardiography failed to demonstrate the second VSD or a residual leak through the patch although a PAC could be passed from the right ventricle to the left ventricle and subsequently into the aorta and right carotid artery.

Conclusion: Correct placement of a PAC should be confirmed by chest radiography or other techniques to prevent complication.

Objectif : Rapporter le cas d'un cathéter artériel pulmonaire (CAP) déplacé dans l'artère carotide après une intervention à coeur ouvert.

Éléments cliniques : Un garçon de 20 mois a subi une opération à coeur ouvert (réparation d'une CIV). Le jour suivant l'opération, il a présenté une hypertension pulmonaire sévère et on a inséré un CAP, sans complication, en passant par la veine jugulaire interne gauche. Deux heures plus tard, une radiographie pulmonaire a révélé la présence du CAP dans l'artère carotide interne droite, position atteinte par les ventricules droit et gauche et l'aorte. On a retiré le CAP et inséré un nouveau cathéter. On a vérifié sa position par une radiographie pulmonaire. Deux ans plus tard, l'échocardiographie n'a pu démontrer une seconde CIV ou une fuite résiduelle provenant de la réparation, bien qu'un CAP puisse passer du ventricule droit au ventricule gauche et ensuite dans l'aorte et l'artère carotide droite.

Conclusion : La mise en place correcte d'un CAP doit être confirmée par une radiographie pulmonaire ou d'autres techniques afin de prévenir toute complication.

From the Department of Anesthesiology and Reanimation, Hacettepe University, Faculty of Medicine, 06100 Ankara, Turkey. Address correspondence to: Meral Kanbak MD. Phone: Work: 90-312-3051987; Home: 90-312-2299829; Fax: 90-312-3109600; E-mail: ok05-k@tr-net.net.tr

Accepted for publication February 2, 2000. 


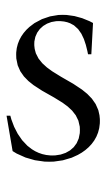

INCE its first use by Swan et al. in 1970, pulmonary artery catheters (PAC) have become widely used to assist in the care of critically ill surgical or medical adult patients, but they have had limited use in pediatric patients. Several complications, including arrhythmias, venous thrombosis, balloon rupture, intracardiac knotting of the catheter, pulmonary artery (PA) injury and misplacement have been described following PA catheterization. ${ }^{1,2}$

We report a case of PAC misplacement into the right carotid artery following insertion via th left internal jugular approach.

\section{Case report}

A 20-mo-old boy was admitted with dyspnea and decreasing effort tolerance. He had a history of ventricular septal defect (VSD) since the age of one month. At cardiac catheterization performed seven months earlier, PA systolic, diastolic, mean, right ventricular, left ventricular and aortic systolic pressures were $50,15,35,75,80$ and $80 \mathrm{mmHg}$ respectively. $\mathrm{He}$ had a pansystolic murmur $3 / 6$ at the left sternal edge and 3rd-4th intercostal space. Two-dimensional (2D)-echocardiography showed a subaortic, $1 \mathrm{~cm}$ enlarged VSD; patent foramen ovale (PFO); and pulmonary hypertension.

He was scheduled for correction of VSD and PFO.

Anesthesia was induced with thiopental, vecuronium bromide and morphine and maintained with isoflurane, $\mathrm{O}_{2}-\mathrm{N}_{2} \mathrm{O}$ and morphine. Cardiopulmonary bypass $(\mathrm{CPB})$ was performed with nonpulsatile perfusion at $26^{\circ} \mathrm{C}$. Following repair of the VSD with a patch and PFO, the patient was weaned from CPB. The aortic cross-clamp and total CPB times were 40 and $50 \mathrm{~min}$, respectively. Surgery was completed without complication and the patient was transferred to the intensive care unit (ICU).

On the first day after surgery, in the ICU, he had a pansystolic murmur. Echocardiography showed no residual leak through the patch and no VSD was demonstrated. The PA gradient was $65 \mathrm{~mm} \mathrm{Hg}$ and it was thought that the severe pulmonary hypertension would benefit from PA pressure monitoring and nitroglycerin (NTG) infusion in a PAC. As the right internal jugular vein (IJV) has been used for central catheterization preoperatively, the sheath was inserted in the left-IJV using the Seldinger technique without complication. A \#5 F PAC was inserted without difficulty and a PA waveform was obtained. When the systolic arterial pressure was $90 \mathrm{~mm} \mathrm{Hg}$, the PA pressure was $90 \mathrm{~mm} \mathrm{Hg}$ and a NTG infusion was started via the PAC. Chest radiography was performed two hours later and demonstrated abnormal placement of the catheter in the right carotid artery (Figure).The PAC was withdrawn and a new PAC was inserted and the PA pressure was $80 \mathrm{~mm} \mathrm{Hg}$. Chest radiography showed correct placement of the second PAC. A NTG infusion was continued for seven days and the patient was discharged on the 27th day after surgery.

Although he had no complaints one month postoperatively, he had a 2/6 pansystolic murmur. A VSD persisted, but neither a residual leak through the patch, nor a second VSD was demonstrated with the $2 \mathrm{D}$-echocardiography. Although he was well, the pansystolic murmur continued and echocardiography was unable to demonstrate the presence of a VSD two years after the operation.

\section{Discussion}

Pulmonary artery catheters play an increasing role in the hemodynamic management of adult patients, but have had limited use in pediatric patients. Insertion of a PAC in this age group is rarely attempted in view of the technical difficulty and risk of serious complications. ${ }^{3}$ Although incorrect placement of the PAC is frequently seen, the incidence of carotid artery puncture is $1.5-2 \%$ and its inadvertent cannulation is less

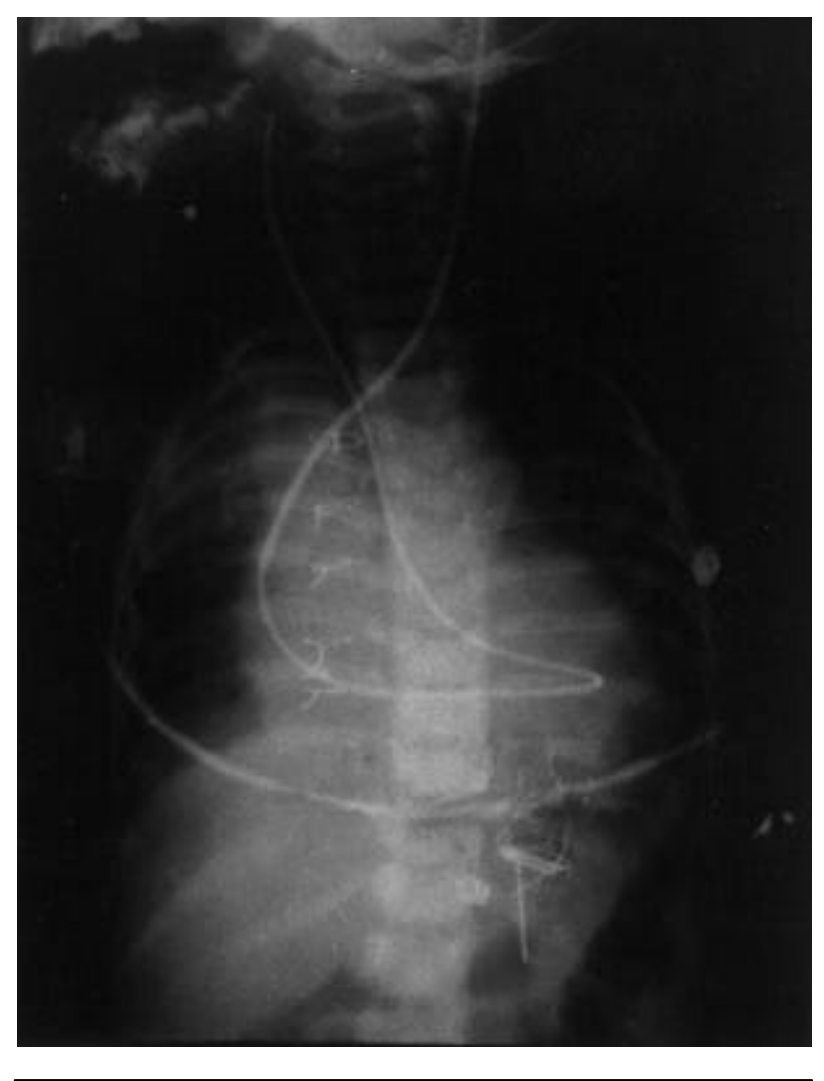

FIGURE Inadvertent placement of PAC: right carotid artery placement via the left internal jugular approach. 
than 1 in 1000 . A carotid artery internal jugular vein fistula has been reported in two cases following internal jugular approach. ${ }^{4}$ Such a complication has not been previously described in the literature.

The PAC catheter may pass into the left side of the heart through an interatrial or interventricular communication and the catheter may enter the aorta through the left ventricular outflow tract. A similar complication has been reported in which the PA catheter passed through a surgical repaired tear in the superior vena cava into the left atrium, through the left ventricle and subsequently into the aorta. ${ }^{5}$

In this case, chest radiography demonstrated misplacement of the PAC into the right carotid artery following insertion via the left IJV approach. The PAC could be passed from left IJV into the right atrium and right ventricle and to the left ventricle via an inter-ventricular communication and was floated distally in the systemic arterial tree ending up in the right carotid artery. The complication should be recognized by the similarity between pulmonary artery and the systemic arterial waveforms and the presence of pulmonary hypertension. A simple method of excluding this complication is to compare the oxygen saturation of blood from the distal PAC port and the systemic arterial line. An alternative method would be to use $\mathrm{x}$-ray imaging to assist correct PAC placement. ${ }^{6,7}$ Transesophageal echocardiography can be used to guide central venous catheter placement in congenital heart surgery. ${ }^{8}$

The presence of intracardiac shunting with a VSD cannot be demonstrated in all affected children by $2 \mathrm{D}$-echocardiography. In a recent study, 77 patients, age one day to $15.5 \mathrm{yr}$ were identified over a two year period as having VSDs by colour-flow Doppler (CFD) mapping; 97 defects were noted by colour-flow imaging that were not visualized by standard 2D-echocardiography. Eleven of the 67 perimembranous VSDs, nine of the 22 muscular defects and none of the subpulmonic defects were identified in any other manner except by CFD imaging. None of the multiple defects were correctly localized or identified by standard 2D or CFD echocardiography. ${ }^{9}$

In our case it is possible that, the patient had a second VSD which could not be demonstrated with 2D echocardiography. Although this second VSD may be demonstrated by cardiac catheterization, due to the lack of symptoms, this has not been performed.

In summary, a PAC introduced via left IJV passed into the right carotid artery. Although it was not recognized immediately, no serious complications have seen. This case suggests that a false sense of security after surgical closure of intracardiac defects may lead to serious complications and correct placement of
PAC must be confirmed by chest radiography or other techniques especially in children.

Acknowledgment

We would like to thank Prof. Dr. Metin Demircin (Cardiovascular surgeon, Hacettepe University Hospital), for his important contributions.

\section{References}

1 Gomez CMH, Palazzo MGA Pulmonary artery catheterization in anaesthesia and intensive care. $\mathrm{Br} \mathrm{J}$ Anaesth 1998; 81: 945-56.

2 Miller JA, Singireddy S, Maldjian P, Baker SR. A reevaluation of the radiographically detectable complications of percutaneous venous access lines inserted by four subcutaneous approaches. Am J Surg 1999; 65: 125-30.

3 McGee WT, Ackerman BL, Rouben LR, Prasad VM, Bandi V, Mallory DL. Accurate placement of central venous catheters: a prospective, randomized, multicenter trial. Crit Care Med 1993; 21: 1118-23.

4 Gobeil F, Couture P, Girard D, Plante R Carotid artery-internal jugular fistula: another complication following pulmonary artery catheterization via the internal jugular venous route (Letter). Anesthesiology 1994; 80: 230-2.

5 Allyn J, Lichtenstein A, Koski EG, Jacobs ML, Lowenstein $E$. Inadvertent passage of a pulmonary artery catheter from the superior vena cava through the left atrium and left ventricle into the aorta. Anesthesiology 1989; 70: 1019-21.

6 Frassinelli P, Pasquale MD, Cipolle MD, Rhodes M Utility of chest radiographs after guidewire exchanges of central venous catheters. Crit Care Med 1998; 26: 611-5.

7 Farrell J, Walshe J, Gellens M, Martin KJ. Complications associated with insertion of jugular venous catheters for hemodialysis: the value of postprocedural radiograph. Am J Kidney Dis 1997; 30: 690-2.

8 Andropoulos DB, Stayer SA, Bent ST, et al. A controlled study of transesophageal echocardiography to guide central venous catheter placement in congenital heart surgery patients. Anesth Analg 1999; 89: 65-70.

9 Sommer RJ, Golinko RJ, Ritter SB. Intracardiac shunting in children with ventricular septal defect: evaluation with Doppler color flow mapping. J Am Coll Cardiol 1990; 16: 1437-44. 